\title{
COULD THERAPEUTIC DIARIES SUPPORT RECOVERY IN PSYCHIATRIC
}

\section{INTENSIVE CARE?}

Yeter Sinem ÜZAR-ÖZÇETIN ${ }^{1}$, Steve TRONEWETH ${ }^{2}$, Louice L. Clark ${ }^{3}$, Greg $\mathrm{HEXT}^{4}$, Stephen TEE

1 Dr Yeter Sinem ÜZAR-ÖZÇETIN RN, Ph.D, Assistant Professor. Hacettepe University Faculty of Nursing Psychiartic Nurisng Department, SihhiyeAnkara/TURKEY 06100. Tel: +3123051580. Email: sinem_uzar@hacettepe.edu.tr

${ }^{2}$ Dr Steve Trenoweth PhD, MSc, PGDipEA, BSc (Hons), RNMH, SFHEA, AFBPsS. Principal Academic, Head of BUiWell Research Centre, Room B412, Bournemouth House Faculty of Health and Social Sciences. Bournemouth University 17 - 19, Christchurch Road, Bournemouth DORSET BH1 3LH.

Email: strenoweth@bournemouth.ac.uk

${ }^{3}$ Louise L. Clark BA MSc RN (Adult) RN(LD) RN(MH) PGCAP. Senior Teaching Fellow in Mental Health \& Intellectual Disability. Florence Nightingale Faculty of Nursing, Midwifery \& Palliative Care. King’s College London. James Clerk Maxwell Building 57, Waterloo Road. London SE1 8WA. Tel:020 78483060.

Email: louise.clark@kcl.ac.uk

${ }^{4}$ Greg Hext BSc MSc RN (Adult). Lead Nurse Marjory Warren Acute Medical Unit, Charing Cross Hospital, Imperial College NHS Healthcare Trust. Email: greg.hext@nhs.net.

5 Professor Stephen Tee DClinP, MA, PGCEA, BA, DPSN, RMN, PFHEA. Executive Dean, Faculty of Health and Social Sciences, Executive Dean, The Business 
School, Bournemouth University, Royal London House, Christchurch Road Bournemouth, Dorset BH1 3LT. UK. Tel: 01202 962114. Mob: 07710848251.

Email: stee@bournemouth.ac.uk

Conflict of Interest: None. 


\begin{abstract}
Despite growing literature surrounding the use of patient diaries in intensive care units within the general healthcare setting and the positive effects these may have on a patient's psychological recovery from such an admission; no studies exist examining the effects of similar patient diaries in psychiatric intensive care units when used with people experiencing an acute exacerbation of psychosis. This paper hypothesises the potential positive effects of diaries kept for patients in psychiatric intensive care units. In the development of strategies to help people in psychiatric crisis understand and manage their own distress and psychological trauma, diaries may be helpful for the prevention of further psychological problems and aid recovery post discharge. Research is required to consider the possible effects of therapeutic diaries and the role of the multidisciplinary team in keeping these within psychiatric intensive care settings.
\end{abstract}

\title{
INTRODUCTION
}

It is internationally recognised that interdisciplinary education and sharing of innovation between specialities, modalities and sectors will shape the future of truly holistic healthcare delivery and drive forward the integrated care agenda (Naylor et al 2016, World Health Organisation [WHO] 2010). This paper will discuss one example of an opportunity to break down the silo approach that persists between physical and mental health disciplines when addressing a person's, often multifactorial, healthcare needs. It is proposed that the significant and long-term psychological harm reducing benefits achieved through the use of therapeutic diary keeping with patients in general hospital Intensive Care Units (ICUs), could 
be replicable and warrants analysis in those experiencing acute psychosis cared for in psychiatric intensive care units.

A significant proportion of survivors from critical illness treated in the ICU within general healthcare settings frequently suffer from anxiety, depression and post-traumatic stress disorder (PTSD) (Egerod and Christensen 2010, Wake \& Kitchiner 2013). Survivors often report amnesia, flashbacks, hallucinations and recurring nightmares post discharge (Roulin et al. 2007) and this group are far less likely to return to their premorbid functionality in day to day living (Jones et al. 2012). Jones et al. (2001) found that delusional memories and large memory voids were a significant factor in the subsequent psychological distress experienced by ICU survivors. The largest multi-centre (26 UK ICUs) study of its kind $(n=13,155)$ examining post critical illness Health Related Quality of Life and psychopathology concluded that over half of the $n=4943$ respondents to a postal questionnaire reported significant symptoms of anxiety (46\%), depression (40\%) and PTSD (22\%) (Hatch et al 2018).

In patients admitted to PICU with an acute psychotic episode, comparisons can be made to those surviving a general ICU admission. Whilst PICUs are associated with a reduction in challenging behaviour and incidents of violence and aggression in the short-term containment, restrictions in movement, sensory deprivation and the organic effects of acute psychosis, can, in the long-term significantly increase a person's traumatic memories of their care and affect their functioning in society post discharge (Vaaler et al 2009). A growing body of work in the reduction of restrictive practices is making head way in the reduction of these harmful phenomena (Department of Health 2014.. Clark et al 2017) and this has now become evident in the general hospital setting (Hext et al 2018, Xrichis et al 2018)' To support this agenda, this article considers potential translational benefits of keeping patient 
diaries in PICU and argues that teams within the PICU settings could add them to their armoury of therapeutic interventions to enhance management and recovery from an acute psychotic episode.

\section{BACKGROUND}

An estimated $30 \%$ of general hospital ICU patients are reported to experience anomalous psychological phenomena during intensive care (Ringdal et al. 2006, Samuelson et al., 2006). Such phenomena may include dreams, nightmares, delusional memories and even hallucinations which may be more vivid and more readily recalled that factual experiences of intensive care. These experiences can have a profound and long-lasting effect on an individual, potentially impacting the trajectory of their post-discharge recovery (Jones et al. 2001, Kiekkas et al. 2010). A recognised diagnosis, post intensive care syndrome (PICS) is defined as a long-term physical (neuromuscular), cognitive or mental health impairment as a result of surviving an ICU admission (Rawal et al 2017). The effects of PICS also go on to have an effect on the family unit and it's functioning as a whole (Davidson et al 2012, Rawal et al 2017). If patients only have delusional memories of time spent in ICU, and no factual memories they are considered to be at an increased risk of developing PTSD (Jones et al. 2001, Jones et al. 2004, Jones et al. 2012). Likewise, this delusional state is argued to result in difficulty for patients recognising what they have undergone and how unwell they have been, this may then lead to unrealistic expectations regarding the recovery process (Griffiths and Jones 2001, Roulin et al 2007).

Patient diaries were first introduced in 1991 in Swedish ICUs (Akerman et al. 2010), to support the patient's recall the ICU stay, which was seen to contribute to better rehabilitation 
and recovery, provide a better understanding of what happened, fill in memory gaps and process events and delusional memories (Akerman et al. 2010). In a non-randomised controlled study Jones et al. (2006) found that ICU diaries might significantly reduce PTSD symptoms in survivors of ICU and continued to make similar postulations in a later study (Jones et al. 2009), however, when viewed critically design errors in this study weakened these assumptions due to only a few former ICU patients $(n=4)$ attending the focus group and little was reported regarding the actual content of the diaries. Former patients did however report that the diary alone provided incomplete information. Nonetheless, there is wealth of qualitative evidence that makes a compelling argument for diary use; patients report many of the aforementioned benefits, helping them to piece together fragmented memories and starting conversations with family members in making sense of their shared traumatic experiences (Backman et al 2010, Garrouste-Orgeas et al 2012).

Diaries are now commonly used in general hospital ICUs across Europe and are increasingly being introduced in ICUs around the UK. The diaries are prospectively written by ICU nurses, other members of the MDT, next of kin and relatives (in the $2^{\text {nd }}$ person). Diaries commence with information pertaining to the reason for admission and the initial support given; subsequent daily entries written by healthcare professionals, in lay terms, detail significant events, changes in condition, routine care that appeared to cause distress or positive landmarks. Families are also encouraged to write in the diaries during the patient's stay, which has subsequently been found to have a significant effect on their own experiences of PTSD and anxiety (Jones et al. 2012). 


\section{The Psychological Impact of Psychiatric Intensive Care}

Significant psychiatric disorders can impact on the psychological, social and vocational functioning of an individual with recurrent episodes sometimes requiring hospital-based treatment in a PICU (Clark \& Cangy, 2016. Clark et al 2017). PICUs provide the most intense level of psychiatric care and treatment (Bowers et al. 2008. Bowers, 2014. Clark \& Cangy. 2016) for patients displaying the highest degree of risk and who are in need of support through containment (Bowers. 2014). These units help reduce symptoms and manage behaviours that may put the patient or others at risk (Pereira et al 2005). They are generally small units, usually up to 12 bedded, with higher nurse/staff: patient ratios, usually locked and low-secure in status and often with seclusion facilities (Bowers et al. 2008, Clark \& Cangy. 2016).

Psychosis is the most common cause of admission to a PICU (Pereira et al. 2005, Clark \& Cangy. 2016), diagnostic sub-categories include schizophrenia and delusional disorders, schizoaffective disorder and transient psychotic episodes - often the result of acute intoxication due to street drugs (Pereira et al. 2005. Clark \& Cangy, 2016. Clark et al 2017). PICU patients are significantly younger than other hospital populations (Brown and Bass 2004), but may range from aged 18 to quite elderly, a survey of London PICU's ( $n=17)$ showed a mean age of 33 years (Pereira et al 2005). The most prevalent reason for transfer to PICU is to contain aggression (Pereira et al. 2005. Clark et al 2017), thereby, patients are potentially considered more likely to be violent (Bowers et al. 2008, Clark \& Cangy. 2016). Many PICU patients have comorbidities in addition to their primary psychiatric diagnosis, 
including misuse of street drugs, aggressive and/or challenging behaviour, social isolation, homelessness, physical health problems and trauma (Pereira et al. 2005, Clark \& Clarke 2014). Such comorbidities can affect length of stay and the recovery process whilst in a PICU.

Arguably, in both ICU and PICU patients are exposed to similar psychosis inducing stressors such as noise, light, unnatural environments, disruption to circadian rhythms and physical or even chemical restraint (Clark \& Cangy, 2016. Clark et al 2017, Hext et al 2018. Xyrichis et al 2018). Therefore, it is plausible that following discharge from PICU service users may encounter issues similar to those who have had been discharged from a general hospital ICU. That is, whilst ICU and PICU environments have many differences in terms of purpose and function, there remain some fundamental similarities in terms of their approach and psychological impact on the individual (See Table $1 \&$ Table 2).

Table 1: Comparable features of care in an ICU or PICU.

\begin{tabular}{|c|c|}
\hline ICU & PICU \\
\hline - Includes multiple intensive and & - Includes intense therapeutic \\
\hline invasive physical interventions and & intervention to manage symptoms \\
\hline polypharmacy & - Period of stay will vary according to \\
\hline - Often, protracted hospital stays & risk of violence \& response to treatment \\
\hline followed by intense rehabilitation & but often lengthened by limited stepdown \\
\hline - Surrounded by technologies, & capacity \\
\hline devices and multiple teams $24 / 7$ to & - Enforced containment \\
\hline manage life supportive measures, & - Compulsory treatment under the \\
\hline
\end{tabular}




\begin{tabular}{|l|l|}
\hline treated in best interests. & Mental Health Act (1983, amended \\
• Restricted mobilisation, possible & 2007). \\
chemical and/or physical restraint in & - Possible restraint and/or seclusion, \\
the acute phases of critical illness. & freedom restricted by virtue of being in a \\
• Patients suffering from physical life & locked unit \\
threatening illnesses, overwhelming & • Patients suffering from psychiatric \\
sepsis or pre and postoperative care & illness often confounded by complex \\
which can contribute to incidence of & psychological and physical health \\
delirium and psychological distress & problems. \\
\hline
\end{tabular}

Table 2: Shared features of ICU and PICU

Shared Features
Being in an unfamiliar/unnatural environment
Treatment given without consent or in best interests
Increased staff: patient ratios
Witness or subject to multiple traumatic stimuli
Often isolated units from other parts of hospital
Limited autonomy of patients in restrictive environments
Traumatic memories post discharge
Increased need for psychological intervention/support
Predisposition to PTSD post discharge
Difficulties interpreting experiences of care
Subsequent familial stress and anxiety


Patient participation in decision making process sometimes significantly reduced

PICU patients often have difficulty recalling the severity of their psychiatric crisis and journey to recovery, resultantly these memory gaps can manifest other psychological symptoms that lengthen or increase recurrence of PICU stays - further exacerbating psychological distress in these individuals (Clark \& Cangy, 2014. Clark et al 2017). It is posited that PICU patients are more likely to suffer from the effects of their admission, especially regarding experiences of physical restraint and/or seclusion (Clark et al 2017). Undetected PTSD may place a person with a diagnosis of psychosis at higher risk of an acute psychiatric crisis and recurrent stays in PICU. Identifying prevalence, treating or preventing PTSD is important because psychological trauma and PTSD are associated with increased risk and severity of other medical conditions, both chronic and acute illnesses (Ford and Fournier 2007).

\section{Diaries and their effects on patients and families}

The body of literature supporting the use of patient diaries in general hospital ICU is growing more compelling and has led to significant uptake in the UK. There are well documented therapeutic benefits that appear to help ICU survivors' bridge memory gaps and make sense of confounding delusional memories and flashbacks (Gjengedal 2010, Jones 2009). Despite this, there would appear to be minimal evidence that systematically assesses the potential for using diaries in PICUs to aid meaningful recovery. 
The ICU patient diary is typically kept at the patient's bedside with photographs securely stored elsewhere. It is, in effect, a daily record of the patient's ICU stay, significant events in the outside world (e.g. favourite football team wins/loses etc.) written in lay language by nurses, members of the multidisciplinary team or nominated relatives (Jones et al. 2012). Following ICU discharge, normally 3 months to a year later patients are offered the opportunity to read and keep the diary. Diaries are non-medicolegal documents that at all times is the property of the patient. If a patient declines to receive the diary it is stored for finite period of time before being destroyed (Jones 2009).

ICU survivors commonly report difficulties discussing their feelings, fears, hallucinations and vivid dreams with others, a phenomenon confounded by lack of insight in to own experiences and fear of being labelled as mentally ill (Engstrom et al. 2008). Survivors have further expressed the need to know and understand the events that took place in the ICU (Adamson et al. 2004, Hupcey and Zimmerman 2000, Richman 2000). ICU diaries can to afford survivors the opportunity to make sense of fragmented memories and promote open dialogue with those around them, allowing survivors to express what they have and continue to experience (Roulin et al. 2007). Diaries, can in this sense be used as a rehabilitation/recovery tool, and are increasingly becoming integral to the care provided to patients in ICUs across the UK and Europe at large (Combe 2005) and there is a growing body of literature supporting this movement (Egerod et al. 2006, Engstrom et al. 2009, Egerod and Christensen 2009, Knowles et al 2008, Löf et al 2008, Jones et al. 2009).

Studies show that amnesia and/or memory fragmentation developed as a result of critical illness and intensive care can lead to long term/chronic health problems (Jones et al. 2001, Scragg et al. 2001, Skirrow et al. 2002, Vaare et al 2009). In this instance diaries may aid 
prevention, promote recovery and go some way to reduce incidence and severity of PTSD (Egerod et al. 2006; Jones et al. 2006). The use of diaries is a simple, cost effective and practical method for the reduction of psychological symptoms and the associated morbidities amongst patients and families having experienced intensive care (Roulin et al. 2007).

\section{The Role of the Mental Health Team in the use of Patient Diaries}

PICU's continue to have an important role in the care of patients with acute psychiatric disorders and often concurrent complex physical health issues (Clark \& Cangy, 2016. Clark et al. 2017). High quality assessment from a bio-psycho-pharmaco-social perspective (Clark \& Clarke, 2014), treatment and proactive care depends on a competent workforce engaging in continuous professional development (Clark \& Cangy. 2016). Research demonstrates that targeted therapeutic activity promotes patient engagement and reduces agitation. Patientnurse communication and cooperation is invaluable in promoting support, respect, empowerment and recovery (Bowers 2014, Clark et al 2017). Unlike the ICU patient, the PICU patient may be able to contribute to their own diary writing at certain times, potentiating wider, yet unknown, therapeutic effects. The writing of a diary may also be incorporated as part of a behavioural support plan, such plans are now a recommendation in the United Kingdom for patients who exhibit challenging behaviour (Department of Health 2014). Clearly the physical and psychological safety of the entire PICU population is central to the nurses role (Björkdahl et al. 2010), nonetheless, nurses have great potential and positioning to promote therapeutic culture within the PICU (Bowers 2014, Clark \& Cangy 2016, Clark et al, 2017). The introduction of diaries may be significant in promoting dialogue between the medical professional, nurse, patient and their families, enabling 
opportunities to express experiences and perceptions. Diaries could help to ameliorate the potential negative impacts a PICU admission may present and form a significant step in more personalised behavioural support planning.

As in ICU, PICU diaries could be a cost-effective, non-invasive intervention that may foster hope and recovery and have the potential to promote insight into the patient experience. Staff can be easily trained in the use of diaries which could encourage focused professional/ patient engagement and ultimately reduce conflict and containment. Diaries may provide PICU survivors some meaning and understanding to their PICU experience.

Care in a PICU should aim to ensure freedom from fear as well as from dehumanising and disempowering experiences (Delaney and Johnson. 2007, 2008). Empowering interventions such as discussion, showing interest and encouragement in the patient are important interventions toward promoting person centred recovery (Pitkenen et al. 2008), diaries could be a useful tool in this approach. Mental health nurses are essential to the provision of 24 hour intensive care and have the opportunity to facilitate positive experiences for patients during PICU admissions and post discharge. If keeping patient diaries for patients with acute psychiatric presentations became routine in PICUs, there may be a reduction in patient distress, restrictive practices, agitation and challenging behaviour during the PICU stay and further psychological problems following discharge. Of course, further research is needed in this area.

\section{CONCLUSION}

Studies report the use of ICU diaries in several European and Nordic Countries including the UK, Sweden, Denmark and Norway. There are many shared commonalities between ICU 
and PICU admissions which this paper has highlighted, and yet diaries are not common in PICU practice. The possible impact of PICU diary use should be evaluated as PICU patients may experience similar psychological effects to their ICU counterparts, so it is likely that diaries could contribute towards behavioural support planning, reduce incidents of aggression and violence and be valuable tool towards recovery.

The often unpredictable nature of the PICU environment has the potential to negatively impact on nursing care, and therefore any intervention that promotes patient engagement has the potential to provide a positive impact. This paper aimed to show the positive role of diaries for PICU patients and the intention of the authors to conduct a pilot study focusing this approach in a number of PICUs in order to determine impact and effectiveness over time. 


\section{REFERENCES}

Adamson H. Murgo M. Boyle M. et al. (2004) Memories of intensive care and experiences of survivors of a critical illness: An interview study. Intensive and Critical Care Nursing 20, 257-263.

Akerman E. Granberg-Axell A. Ersson A. et al. (2010) Use and practice of patient diaries in Swedish intensive care units: a national survey. British Association of Critical Care Nurses, Nursing in Critical Care 15(1), 26-33.

Backman C.G., Orwelius L., Fredrikson, M., et al. (2010) Long-term effect of the ICU-diary concept on quality of life after critical illness. Acta Anaesthesiologica Scandinavica 54(6), 736-743.

Björkdahl A. Palmstiernat T. Hansebo G. (2010) The bulldozer and the ballet dancer: aspects of nurses' caring approaches in acute psychiatric intensive care. Journal of Psychiatric and Mental Health Nursing 17, 510-518.

Bowers L. Jeffery D. Bilgin H. et al. (2008). Psychiatric intensive care units: a literature review. International Journal of Social Psychiatry 54(1), 56-68.

Bowers L. (2014) Safewards: a new model of conflict and containment on psychiatric wards. Journal of Psychiatric \& Mental Health Nursing. 21:499-508

Brown S. \& Bass N. (2004) The psychiatric intensive care unit (PICU): Patient : 
Carroll S.M. (2004) Nonvocal ventilated patients perceptions of being understood. Western Journal of Nursing Research 26, 85-103.

Clark L.L. \& Clarke T (2014) Realising nursing: a multimodal approach to psychiatric nursing. Journal of Psychiatric \& Mental Health Nursing 21(6): 564-571

Clark L.L. \& Cangy J. (2016) Person-centred approaches in inpatient, acute, emergency and intensive psychiatric care. In Tee S. (Ed) Person-Centred Approaches in Healthcare: A handbook for nurses \& midwives. McGraw Hill 237-252.

Clark L.L.. Shurmer D.. Kowara D.. \& Nnatu I (2017) Reducing restrictive practice: Developing \& implementing behavioural support plans. British Journal of Mental health Nursing:6(1) 22-28.

Combe D. (2005) The use of patient diaries in an intensive care unit. Nursing in Critical Care 10(1), 31-34.

Davidson J.E. Jones C. Bienvenu O.J. (2012) Family response to critical illness: post intensive care syndrome-family. Critical Care Medicine 40(2), 618-624.

Delaney K.R. \& Johnson M.E. (2007) Inpatient Psychiatric Nurses Need to Speak Up. Archives of Psychiatric Nursing 21(5), 288-290.

Delaney K.R. \& Johnson M.E. (2008) Inpatient psychiatric nursing: why safety must be the key deliverable. Archives of Psychiatric Nursing 22, 386-388.

Department of Health (2014) Positive \& proactive care: reducing the need for restrictive interventions. Department of Health. London.

Egerod I. \& Christensen D. (2010) A comparative study of ICU Patient Diaries vs. Hospital Charts. Qualitative Health Research 22(10), 1446-1456.

Egerod I. Schwartz-Nielsen K.H. Hansen G.M. et al. (2006) The extent and application of patient diaries in Danish ICUs in 2006. British Association of Critical Care Nursing, Nursing in Critical Care 12(3), 159-167. 
Engstrom A. Anderson S. Soderberg S. (2008) Revisiting the ICU experiences of follow up visits to an ICU after discharge: a qualitative study. Intensive and Critical Care Nursing 24, 233-241.

Engstrom A. Grip K. Hamren M. (2009) Experiences of intensive care unit diaries: 'touching a tender wound'. British Association of Critical Care Nursing, Nursing in Critical Care 14(2), 61-67.

Ford J.D \& Fournier D. (2007) Psychological trauma and post-traumatic stress disorder among women in community mental health aftercare following psychiatric intensive care. Journal of Psychiatric Intensive Care 3(1): 27-34.

Garrouste-Orgeas M. Coquet I. Periera et al (2012). Impact of an intensive care unit diary on psychological distress in patients and relatives. Critical Care Medicine 40(7) 2033-2040.

Gjengedal E. Storli S.L. Holma A.N. et al. (2010) An act of caring - patient diaries in Norwegian intensive care units. Nursing in Critical Care 15(4), 176-184.

Griffiths R.D. \& Jones C. (2001) Filling in the intensive care memory gap. Intensive Care Medicine: 27; 344-346.

Hatch R., Young D., Barber., et al (2018) Anxiety, Depression and Post Traumatic Stress Disorder after critical illness: a UK-wide prospective cohort study. Critical Care 22 (310).

Hext G. Clark L.L. \& Xrichis A (2018). Reducing restrictive practice in adult services: not only an issue for mental health nurses. British Journal of Nursing.27(7) 479-484.

Hupcey J. \& Zimmerman H. (2000). The need to know: Experiences of critically ill patients. American Journal of Critical Care 9, 192-198.

Jones C. Griffiths R.D. Humphris G. Skirrow P.M. (2001). Memory, delusions and the development of acute posttraumatic stress disorder related symptoms after intensive care. Critical Care Medicine: 29; 573-580.

Jones C. (2009) Introducing photo diaries for ICU patients. JICS 10(3), 183-185. 
Jones C. Backman C. Griffiths R.D. (2012) Intensive care diaries and relatives' symptoms of Posttraumatic Stress Disorder after critical illness: a pilot study. American Journal of Critical Care 21(3), 172-176.

Jones C. Griffiths R.D. Slater T. et al. (2006) Significant cognitive dysfunction in nondelirious patients identified during and persisting following critical illness. Intensive Care Medicine 32, 923-926.

Jones C. Skirrow P. Griffiths R.D. et al. (2004) Post-traumatic stress disorder-related symptoms in relatives of patients following intensive care. Intensive Care Medicine 30(3), 456-460.

Kiekkas P. Theodorakopoulou G. Spyratos F. Baltopoulos G. (2010) Psychological distress and delusional memories after critical care: a literature review International Nursing Review 57 (3), 288-96.

Knowles R.E. \& Tarrier N. (2008) Evaluation of the effect of prospective patient diaries on emotional well-being in intensive care unit survivors: A randomized controlled trial. Critical Care Medicine 37(1), 184-191.

Löf L. Berggrena L. Ahlströmc G. (2008) ICU patients' recall of emotional reactions in the trajectory from falling critically ill to hospital discharge: Follow-ups after 3 and 12 months. Intensive and Critical Care Nursing 24, 108-121.

Mental Health Act (1983) amended (2007) Mental Health Act 1983 (amended 2007), London, HMSO.

Naylor C., Das P., Ross S., et al (2016) Bringing together physical and mental health: a new frontier in for integrated care. The King’s Fund: London.

Pereira S., Sarsam S., Bhui K., et al. (2005) The London Survey of Psychiatric Intensive Care Units: psychiatric intensive care; patient characteristics and pathways for admission and discharge. Journal of Psychiatric Intensive Care 1(1), 17-24. 
Pitkenen A., Hatonen H., Kuosmanen L., et al. (2008) Patients' descriptions of nursing interventions supporting quality of life in acute psychiatric wards: a qualitative study. International Journal of Nursing Studies 45, 1598-1606.

Rawal G., Yadav S. \& Kumar R. (2017) Post intensive care syndrome: an overview. Journal of Translational Internal Medicine. 5(2), 90-92.

Richman J. (2000). Coming out of intensive care crazy: Dreams of affliction. Qualitative Health Research 10, 84-102.

Ringdal M, Johansson L, Lundberg D, Bergbom I. (2006). Delusional memories from the intensive care unit- experienced by patients with physical trauma. Intensive and critical care nursing: 22; 346-354.

Roulin M.J., Hurst S., Spring R. (2007) Diaries written for ICU patients. Qualitative Health Research 17(7), 893-901.

Samuelson K., Lundberg D., Fridlund B. (2006) Memory in relation to depth of sedation in adult mechanically ventilated intensive care patients. Intensive Care Medicine 32, 660-667.

Scragg P., Jones A., Fauvel N. (2001) Psychological problems following ICU treatment. Anaesthesia 56, 9-14.

Skirrow P., Jones C., Griffiths, R.D. et al. (2002) The impact of current media events on hallucinatory content: The experience of the intensive care unit (ICU) patient. British Journal of Clinical Psychology 41, 87-91.

Vaaler A., Morken G., Flovig J., et al (2009) Effects of a psychiatric intensive care unit in an acute psychiatric department. Nordic Journal of Psychiatry. 60(2), 144-149.

Wake S. \& Kitchiner D. (2013) Post traumatic stress disorder after intensive care. BMJ 346.

WHO | framework for action on interprofessional education and collaborative practice [homepage on the Internet] World Health Organization, Department of Human Resources for 
Health; Geneva, Switzerland: [cited 8/21/2010]. 2010. Available from: http://www.who.int/hrh/resources/framework_action/en/index.html.

Xyrichis A. Hext G. \& Clark L.L. (2018) Beyond restraint: Raising awareness of restrictive practices in acute care. International Journal of Nursing studies.

doi:10.1016/j.ijnurstu.2018.06.006.Epub 2018 Jun 8. 